\title{
REPETIÇÕES NA SALA DE AULA DE LÍNGUA ESTRANGEIRA: Uma análise microetnográfica
}

\section{Simone Correia Tostes ${ }^{(*)}$}

Resumo: Estudo sobre os recursos de repetição utilizados pelo professor de língua estrangeira inglês. A pesquisa realizada demonstrou serem as repetições valiosas para a interação professor-aluno, em ambiente de ensino-aprendizagem em que a LE constitui o veículo de comunicação. Entrevistas com o docente evidenciaram que esses recursos não são conscientes, embora sua eficácia tenha sido julgada indiscutível com alunos em fases incipientes de aprendizagem de LE.

Palavras-chave: Ensino; interação; metalinguagem; repetições

Este estudo tem por finalidade estudar as funções das repetições no contexto de ensino-aprendizagem de inglês como língua estrangeira. Adotamos a perspectiva de análise sócio-interacional de Gumperz, segundo a qual nenhum discurso pode ser analisado desvinculado de seu contexto sócio-comunicativo.

Segundo as máximas conversacionais de Grice, um dos princípios que devem ser observados durante interações é a máxima da quantidade, isto é, o sujeito deve expressar o necessário para ser compreendido por seu interlocutor, nem mais nem menos, sob pena de ser redundante ou reticente, respectivamente.

Entretanto, a análise de diversos contextos em que repetições são constantes leva-nos a afirmar que, a depender dos contextos interacionais, repetições passam a cumprir papéis importantes na comunicação. No discurso docente, por exemplo, em que a comunicação é estabelecida na língua-alvo (situações de ensinoaprendizagem de inglês que pressupõem o uso da língua estrangeira desde estágios muito incipientes), a repetição de enunciados pode atender a diversas finalidades, conforme levantadas por Tannen (1989).

Para estudarmos este tipo de contexto, utilizaremos a transcrição de uma atividade de aula de quarenta e cinco minutos da

(“) Doutoranda em Linguística pela UFRJ. 
disciplina Língua Inglesa, ministrada em estabelecimento de ensino público federal. A aula foi gravada com a autorização prévia da professora e dos alunos da turma, que concordaram em contribuir para um trabalho de pesquisa realizado em 1997.

\section{Pressupostos teóricos}

Os pressupostos teóricos deste estudo servirão para nortear questionamentos, assim como conclusões a que chegaremos ao final da análise de nosso objeto de estudo. Iniciaremos com uma reflexão das máximas conversacionais elaboradas por H. P. Grice (1975), a fim de questionarmos a aparente violação da máxima de quantidade (quantity) do discurso redundante e repetitivo do professor.

Em seguida, verificaremos os aspectos da contextualização e da compreensão, conforme estudados por Gumperz (1992), que explicam a correlação indissociável entre o enunciado e o contexto em que se inscreve o mesmo.

Depois, apresentaremos as principais funções e formas que as repetições podem assumir no discurso. Tomaremos por base os estudos de Deborah Tannen (1989).

Por último, explicitaremos o modelo de análise adotado para esta pesquisa, que pretende aplicar a metodologia da pesquisal sóciointeracional, que se carateriza pela micro-análise etnográfica. Esse modelo permite ao analista confrontar sua interpretação dos dados com as reações e objetivos dos falantes ao entrarem em contato com o evento estudado.

\subsection{Revendo as máximas conversacionais}

Grice formulou o que é convencionalmente conhecido como as "máximas conversacionais", isto é, um conjunto de princípios que seguem o arquiprincípio - o Princípio Cooperativo -, que, em síntese, prevê que as contribuições conversacionais dos usuários devem atender ao propósito ou direcionamento da conversa. Grice sintetizou essas máximas em quatro categorias: Quantidade, Qualidade, Relevância e Modo.

A máxima da quantidade prevê que o usuário deve fazer sua contribuição tão informativa quanto necessário. Isto significa que não deve fornecer informações a mais ou a menos em relação ao assunto tratado nas trocas conversacionais. Foi explicitada em duas máximas: 
1. Faça sua contribuição tão informativa quanto necessário;

2. Não faça sua contribuição mais informativa do que o necessário.

Grice salienta que a segunda máxima pode ser discutível, na medida em que se poderia afirmar que o usuário da língua não estaria violando o Princípio da Cooperação, mas apenas sendo prolixo. E argumenta que esse excesso de informação pode induzir os ouvintes a atribuírem um objetivo específico, ao passo que se trata simplesmente de informação excessiva sobre um tema.

A segunda categoria diz respeito à qualidade das contribuições. Para ela existe uma supermáxima - tente fazer contribuições verdadeiras - e outras duas máximas:

1. Não diga o que acredita ser falso;

2. Não diga algo para o qual você não tem evidência suficiente.

A terceira categoria pode ser compreendida através da máxima "Seja relevante".

A quarta categoria está relacionada ao como algo é dito e inclui também uma supermáxima - seja objetivo -, além de outras máximas,

1. Evite obscuridade de expressão;

2. Evite ambigüidade;

3. Seja breve (evite prolixidade);

4. Seja ordenado.

Grice ressalta que enquanto esse esquema se aplica a alguns casos de trocas conversacionais, existem outros, tais como brigas e discurso de carta, em que elas não se adaptam confortavelmente.

O autor ainda prevê situações em que essas categorias podem ser violadas deliberadamente pelo falante. Cita, por exemplo, que o falante pode entrar num choque de máximas ao tentar obedecer a máxima de quantidade e a de qualidade ao mesmo tempo. O falante pode ser incapaz de atender a máxima de quantidade sem violar a máxima de qualidade, por exemplo. Numa interação em sala da aula, em que o professor julga necessário explicitar fatos anteriores ao início da Segunda Grande Guerra, por exemplo, ele pode estar violando a categoria quantidade; por outro lado, essa aparente 
transgressão do princípio de cooperação visa a atender outra categoria - a da qualidade.

Nessas situações, emerge outro conceito de implicatura conversacional e, nesse caso, ao invés de violada, uma máxima estará sendo explorada. Grice elabora um modelo geral para a compreensão da implicatura conversacional:

Ele disse que $p$; não existe razão para supor que ele não esteja observando as máximas, ou pelo menos o Princípio da Cooperação; ele não poderia estar fazendo isso, a menos que ele pense que $q$; ele sabe (e sabe que eu sei que ele sabe) que eu posso ver que a suposição de que ele pensa que $q$ É exigida; ele não fez nada para fazer com que eu parasse de pensar que $q$; ele pretende que eu pense, ou pelo menos deseja permitir que eu pense que $q$; e assim ele implicou que $q$ (GRICE, 1975, p.50, tradução nossa).

Ao discutirmos a aparente violação da máxima da quantidade no discurso do professor neste estudo, podemos manter em mente essa noção de implicatura conversacional formulada por Grice.

\subsection{Contextualizando o discurso}

Gumperz (1992) estabeleceu a importância de se verificar o contexto em que se produz a linguagem a fim de compreendê-la melhor. É através de estudiosos, como Gumperz, que a noção de inferência foi ampliada para abranger os antecedentes culturais e as expectativas sociais necessárias para se interpretar o discurso.

A noção de "pista de contextualização" inclui quaisquer recursos verbais e não-verbais que permitem ao emissor direcionar sua produção lingüística, possibilitando ao ouvinte fazer inferências. Dessa forma, o trabalho de Gumperz sobressai por ser o que inclui aspectos intelectuais, sociais e morais em seu modelo de análise.

O termo contextualização é, então, utilizado para referir-se a sinais verbais e não-verbais, para associar o que está sendo dito a quaisquer outras experiências anteriores dos falantes. Gumperz associa a compreensão da noção de contextualização a uma teoria da interpretação que possui os seguintes princípios: (a) a interpretação é situada e depende do contexto, restrito a como algo é dito e interpretado; (b) o processo de inferência é baseado em um processo de interpretação localizado, e não como verdades absolutas; (c) embora as 
pressuposições sejam feitas com base num referencial extra-lingüístico, esse conhecimento é reinterpretado em cada interação, a fim de que seja socialmente construído.

Gumperz explicita que a elaboração dessa teoria deve

possibilitar a demonstração de como o conhecimento gramatical e o conhecimento do uso da linguagem e convenções retóricas entram na conduta de encontros verbais e desenvolver uma abordagem para a análise conversacional que dê conta do processo interativo que subjaz à percepção de sinais comunicativos e então afetam significativamente a compreensão e a persuasão na conversa do dia-a-dia (p. 231) [tradução nossa].

\subsection{Repetições no discurso (docente)}

Em seu estudo sobre repetições, Tannen (1989) afirma que a repetição está no "coração da linguagem". Ainda assim, a autora adverte que poucos estudos focalizaram a repetição e outras modalidades de textos não-formais. Segundo a autora, a documentação de estratégias individuais e culturais de repetição permanece uma área de pesquisa relativamente inexplorada e promissora.

Tannen apresenta um questionamento básico no que concerne à repetição. Por que alguém gasta sua respiração dizendo a mesma coisa várias vezes? Aparentemente, não há finalidade em repetir o que já foi expresso anteriormente, mas as repetições no discurso podem cumprir várias finalidades.

A autora faz referência a atitudes negativas em relação a repetições. Existe pouca tolerância à repetição de discurso. Um dos exemplos comuns é a intolerância à propaganda eleitoral no rádio e na televisão, principalmente quando a mesma propaganda é repetida duas ou três vezes seguidas. Em outros contextos, daí a importância da contextualização de todas as formas de discurso, a repetição é bastante "tolerada" e até necessária para a construção do significado. Essa é a hipótese que temos para a repetição no discurso docente.

A situação de ensino-aprendizagem é institucionalizada e, estando o aprendiz no nível iniciante de domínio da língua-alvo, é esperado que o professor faça uso extensivo das repetições, uma vez que as mesmas reapresentam estruturas na língua estrangeira (a) 
essenciais para os alunos com maior dificuldade de compreensão do discurso oral e (b) úteis para a retenção da estrutura por aqueles que a compreenderam logo de início. Além disso, as repetições do professor implicam ressaltar que a forma da estrutura e sua pronúncia são importantes.

Tannen elenca vários objetivos que a repetição atende no discurso corrente: (a) produção, (b) compreensão, (c) coesão, (d) interação. A repetição para a produção é convencional para indivíduos e culturas para as quais o silêncio deve ser evitado e a verbosidade é valorizada. A repetição nessas culturas também possibilita ao falante refletir melhor sobre o que dirá em seguida.

A facilitação da compreensão é o segundo objetivo alcançado pela repetição, ao fornecer um discurso menos denso ao ouvinte. Em conseqüência a redundância no discurso permite ao ouvinte compreendê-lo quase na mesma velocidade em que é produzido. Na gama de repetições, Tannen inclui as variações, que, neste estudo, consideraremos como paráfrases. Esse objetivo é amplamente explorado na aula de língua estrangeira ora estudada: a professora repete, modifica e parafraseia.

O terceiro objetivo das repetições consiste na produção de discurso coeso (connection). Cumprem uma função referencial e de ligação, segundo Haliday e Hasan (1976, apud TANNEN 1989). De forma mais sutil, a repetição evidencia uma atitude e uma avaliação do falante. A nosso ver, essa função torna-se evidente no discurso docente que analisaremos mais adiante; no nível iniciante de ensinoaprendizagem a repetição demonstra a preocupação do falante em ser compreendido pelos ouvintes, bem como sua avaliação do nível de fluência do ouvinte, que, nesse estágio, é incipiente.

A repetição também cumpre papel interativo, ao permitir o alcance de propósitos sociais ou simplesmente por permitir que o falante estabeleça uma conversa. Esse último propósito da repetição inclui todos os demais, por ser mais geral e abrangente, isto é, a interação pode ser compreendida como um arqui-propósito da comunicação, envolvendo os participantes na interação discursiva e possibilitando relacionamentos interpessoais.

Tannen distingue dois tipos de repetição - auto-repetição (self-repetition) e repetição de outros (allo-repetition). Outra variação diz respeito à escala de fixação das repetições, variando das repetições 
exatas de enunciados precedentes, passando por repetições com variações (que incluem as reapresentações de perguntas como afirmações, mudança de uma palavra no enunciado e repetição com mudança de pessoa ou tempo verbal), até atingir o nível da paráfrase (repetição de idéias com palavras diferentes). Chamaremos de repetições tanto os enunciados recorrentes com a mesma composição morfofonêmica, bem como as paráfrases, que ocorrem quando o professor reapresenta um conteúdo apenas revendo a forma como o faz, escolhendo estruturas menos complexas e mais próximas da língua materna do aprendiz.

Em seu estudo, a autora aponta a limitação de não apresentar todos os tipos e estilos de repetição, tendo como foco de interesse apresentar algumas funções associadas à repetição, bem como o fato de que está amplamente difundida no discurso, sendo um recurso comunicativo por vezes automático e inconsciente.

Ao tratar da repetição fonológica, por exemplo, Tannen não menciona o alongamento de fonemas durante a produção do enunciado, que incluiremos nessa categoria, pois trata-se de um recurso que permite ao aprendiz na sala de aula de língua estrangeira aproximar recepção e compreensão de enunciados na língua-alvo. $\mathrm{Na}$ gravação de aula aqui analisada, a professora faz uso desse recurso, que, a nosso ver, possibilita o acompanhamento do discurso proferido pela maioria dos alunos.

\subsection{A microanálise etnográfica}

A metodologia de estudo adotada nesta pesquisa pretendeu exercitar princípios da micro-análise etnográfica. Segundo Erickson (1988), esse modelo de análise busca verificar aspectos do significado não imediatamente acessíveis em dados da memória consciente dos informantes.

Conforme salienta esse autor, a etnografia considera essencial para a pesquisa "a fala que ocorre naturalmente, considerada como um modo de atividade social que é situado, bem como a cena imediata da vida social local, na qual a fala em si ocorreu."

O autor destaca o foco no particular como traço primordial da etnografia:

A descrição etnográfica na pesquisa sociolinguiística tem como um interesse central os detalhes do desempenho 
situado, tal como ocorre naturalmente nas interações da vida diária. A etnografia documenta o que as pessoas realmente fazem ao falar e descreve, de modo muito específico, a fala e as situações de uso.

O principal método de coleta de dados da etnografia é a observação participante, segundo a qual o pesquisador integra e observa o evento estudado. Esse método é comumente combinado com gravações em áudio e/ou vídeo e entrevistas informais. O presente trabalho apresenta a limitação de não ter sido realizado através de observação participante. Entretanto, na época em que realizamos a gravação estudada e analisada aqui, constituíamos o grupo de professores de Ensino Fundamental e Ensino Médio que trabalhavam a abordagem comunicativa de ensino de línguas nesses níveis de ensino. Assim, podemos falar com propriedade das atividades desenvolvidas na sala de aula de língua estrangeira e do porquê de se escolherem certas formas em detrimento de outras no processo de ensino de estruturas lingüísticas da língua estrangeira alvo.

Naquela ocasião, consideramos mais eficaz não participarmos dos eventos gravados para a amostra, uma vez que acreditávamos que a presença de um observador não inscrito no processo ensinoaprendizagem comprometeria a desenvoltura com que professores e alunos realizariam suas atividades. O comportamento dos alunos foi visivelmente afetado apenas pela colocação de um gravador próximo ao quadro-de-giz, o que demandou esforços da professora no sentido de conscientizá-los de que a gravação deveria ser esquecida, "não tinha importância" para eles, uma vez que visava a atender propósitos acadêmicos da pesquisa.

Atendemos ao propósito da triangulação de dados da pesquisa etnográfica (cujo objetivo é apresentar evidências a partir do ponto de vista dos participantes) ao realizarmos entrevista informal com a professora, situações em que a mesma apresentou possíveis razões por que se utilizava das repetições em sala de aula e concluiu que não tinha consciência desses processos.

Em síntese, a metodologia de micro-análise etnográfica permitiu-nos uma compreensão integrada de linguagem e vida social naquele grupo particular. 


\section{Descrição etnográfica}

A aula, objeto de estudo desta micro-análise, foi gravada em áudio no segundo semestre de 1997. Naquela ocasião, nosso foco de interesse de pesquisa era a descrição utilizada pelo professor de língua estrangeira sobre estruturas da língua-alvo, feitas nessa língua. Essa aula constitui a amostra pessoal utilizada por Silva (1998) em sua dissertação de mestrado.

A professora desta aula é concursada e trabalha em estabelecimento de ensino federal. Estava nessa instituição há três anos na época em que se realizaram as gravações, ministrando aulas para a $5^{\text {a }}$ série do Ensino Fundamental. Antes, a professora teve experiência em escolas da rede municipal e estadual do Rio de Janeiro.

Nesse colégio federal, localizado na Zona Norte do Rio de Janeiro, os alunos são oriundos de várias origens. Boa parte dos alunos são matriculados nesse estabelecimento de ensino por serem filhos ou dependentes de militares transferidos de outras regiões do país. Outra parcela de alunos é constituída de aprovados em processo seletivo para a $5^{\mathrm{a}}$ série do Ensino Fundamental.

Ao se matricularem nessa série, os alunos são automaticamente admitidos no primeiro nível do sistema de ensino de inglês por níveis, denominado Iniciante A. Esse é o primeiro dos oito níveis de inglês oferecidos por essa instituição de ensino. O sistema de ensinoaprendizagem de inglês por níveis corre paralelamente ao sistema seriado. Assim, o aluno pode ser reprovado em qualquer um dos níveis, sem que isso implique sua repetição na série cursada. Se a reprovação no mesmo nível ocorrer mais de uma vez, o aluno fica retido na série, independentemente de seu rendimento nas outras disciplinas. Outra situação possível é a aprovação para o nível seguinte, mesmo sendo reprovado na série escolar, em decorrência de seu pouco rendimento nas outras disciplinas.

Essas condições de avanço são levadas ao conhecimento do aluno no início do ano letivo, e seu rendimento é acompanhado não somente em relação a resultados obtidos em exames formais, como provas escritas e provas orais. São considerados, além desses resultados, seu desempenho nas aulas, a freqüência com que apresenti as atividades escolares realizadas, sua participação na aula e seu rendimento em atividades de escrita, tais como a elaboração de 
redações, diálogos e projetos, dependendo do nível em que estiver inscrito.

Ao final do ano letivo, os alunos são julgados aptos ou não a avançar para o próximo nível, após verificadas as médias obtidas no seu desempenho oral, escrito, em leitura, bem como na sua compreensão auditiva.

Selecionamos a aula em questão para análise pelo fato de a professora ainda integrar o corpo docente da instituição, sendo possível fazer o confronto entre a análise das gravações. Os nomes dos alunos foram mantidos na transcrição da aula pelo fato de que muitos deles já não se encontram mais no colégio, estão em outras séries e turmas de inglês.

Os alunos são, então, classificados e inscritos para o primeiro nível do sistema na $5^{a}$ série do Ensino Fundamental. Estão todos na faixa etária entre 10 e 12 anos de idade, e a maioria tem seu contato com o idioma estrangeiro em situação de ensino-aprendizagem pela primeira vez nessa fase. Na época em que foram realizadas as gravações da amostra, as turmas de aula nesse colégio eram compostas de, no máximo, vinte alunos.

O sistema de ensino de inglês por níveis nesse colégio prevê que o aluno seja exposto, bem como faça uso do idioma estrangeiro desde fases incipientes de aprendizagem. Dessa forma, utiliza-se a abordagem comunicativa de ensino de línguas. O professor, entĩo. deve se esforçar para utilizar a língua estrangeira para se comunicar nas situações de ensino-aprendizagem.

Para ser compreendido nesse idioma, é natural que o professor realize simplificações em seu discurso. Essas simplificações são acompanhadas de outros recursos, que são, por vezes, inconscientes. tais como a repetição, que analisaremos neste estudo.

O professor tem de usar a língua estrangeira como ponto de partida da introdução de uma nova função comunicativa na línguatalvo. Com isso, seu esforço linguístico e para-linguístico deve ser redobrado, de forma que seja compreendido. Com isso, os recursos que deve utilizar incluem a redução na velocidade de fala, o recurso i tradução imediata, bem como as repetições. 


\section{Análise do evento}

O evento de aula estudado pôde ser dividido em atividades: chamada; conscientização da turma; apresentação da turma à professora; apresentação de situação do livro-texto; exercício em duplas; retomada do trabalho em grupo.

Na primeira atividade, a professora faz a chamada e verifica os alunos presentes; em seguida, o aluno chefe da turma apresenta a turma pronta para a aula; depois, a professora tentar deixar mais claro para os alunos o objetivo da gravação da aula. Em seguida, inicia-se o trabalho com a estrutura do present continuous, seguida de uma atividade em que os alunos trabalham em duplas e utilizam a estrutura praticada na aula.

A análise do evento foi feita com base na audição e na transcrição da gravação. Verificamos que as repetições realizadas pelo discurso docente atendem a duas finalidades principais: pedidos e reiteração/avaliação. Essas incluem a tradução (que seriam melhor compreendidas como paráfrases, na medida em que repetem o conteúdo semântico utilizando uma outra estrutura) bem como o alongamento fonológico.

\section{Pedidos}

Definiremos como pedidos as perguntas feitas pela professora que demandam uma resposta dos alunos, bem como a solicitação de que se realize uma atividade. Por diversas vezes, a professora utilizouse de pedidos repetidos, seja através da repetição integral ou parcial do enunciado, seja pela modificação ou paráfrase/tradução do mesmo. Vejamos os excertos que se seguem:

(80)Is she drinking coke?

(xxvi)SS: No.

(81)T: Is she drinking coke?

(xxvii)S: No.

(82)T: Is she drinking coke?

Nesta passagem, a professora apresenta a pergunta sobre a ilustração três vezes. Essas repetições podem ter sido geradas pelas respostas incompletas dos alunos às perguntas anteriores. Dessa forma, a professora não somente apresenta o pedido mais de uma vez, 
como também avalia que a resposta $N o$ apresentada pelos alunos precisa ser completada com mais informações. pedido:

Em outra passagem, a professora recorre à tradução do

(192)For you to check these pictures here,

(193)You know?

(194)These pictures?

(1)S: Hum? Quê?

(195)T: These pictures.

(196) Os quadrinhos, ok?

(197)You know?

(198)These small pictures here.

Antes de realizar a tradução do pedido para que os alunos observem os quadrinhos, ela recorre a uma versão reduzida do enunciado (cf. 1.194 e 195). Em seguida, traduz o pedido de forma objetiva para elucidar a que se refere e realiza um fechamento do pedido com um enunciado completo (1. 198).

O outro recurso de que se vale o professor pela repetição é a modificação (que aqui pode ser vista como uma simplificação do enunciado):

(281)What's Mrs. Ford doing?

(282) What is she doing, class?

(283)She's what...?

(284)Here.

(285)She's what...?

Note-se que a professora recorre a uma pergunta não comum na língua inglesa, com a palavra interrogativa deslocada para o fim da frase (comum para denotar surpresa, com a entonação ascendente no final da frase). Na situação em questão, a professora realizou uma $w / h$ question (pergunta com palavras interrogativas), com entonação descendente, mas com inversão da ordem prevista para esse tipo de enunciado. 


\section{Reiterações}

A outra função realizada pelas repetições no discurso docente será aqui denominada reiteração ou avaliação, na medida em que denotam a aceitação da produção oral dos alunos para o atendimento adequado a um pedido. Vejamos a sequiência a seguir:

(123)Read.

(124)The verb is read.

(125)He is (...)?

(xxxvii)S Reading a newspaper.

(126)T: Reading a newspaper.

(127)That's right.

(128)He's reading a newspaper, ok?

Nessa situação, há um reforço ou avaliação positiva da resposta do aluno, que é reapresentada mais de uma vez, servindo como reapresentação, que possibilita a compreensão auditiva de alunos com mais dificuldade.

A reiteração pode ser modificada para apresentar uma correção da pronúncia de segmentos fonológicos, conforme verificamos a seguir:

(lxiii)S: She is claining (the house).

(286)T: Cleaning the house, yes,

(287)She's, she's working,

(288)Now, probably she came back,

(289)She's now at home,

(290)But what's she doing?

(291)She is cleaning the house [com voz enfáticia. ressaltando a repetição do fato]

Apesar de ter sido pouco utilizada pela professora na aula analisada, outra modalidade de repetição - o alongamento fonológico - foi provavelmente utilizada para facilitar a compreensão de enunciados, provocando uma diminuição no ritmo da fala e possibilitando aos interlocutores acompanhar o raciocínio juntamente com a fala. 
128 LEITURA - ESPAÇOS HÍBRIDOS: n.28, jul./dez. 2001; n.29, jan./jun. 2002

(315)T: Twenty after fou::r.

(316)Ok, so,

(317)It's twenty after four.

Outra passagem em que se verifica esse tipo de repetição é a que se segue, depois acompanhada de uma paráfrase (cf. 1. 325):

(320)T: What's she doing, class?

(321)Goo:::d.

(322)She's...?

$(\mathrm{xxx})$

(lxix)S: Working.

(323)T: Working, in a way,

(324) She's sho:pping.

(325)She's at the supermarket.

Essas repetições também podem servir como attention getters, pois modificam o ritmo da fala e chamam a atenção do ouvinte para o que está sendo anunciado. Veja o fragmento a seguir, em que se verifica essa função do alongamento fonológico:

(82)T: Is she drinking coke?

(83)T: No.

(84)Uh-uh.

(85) But:::

(86)What's she doing, class?

Mais adiante, verifica-se outra ocorrência dessa função:

(328)T: He is what?

(329)He is helping his wife?

(lxxi)S: No.

(330)T No:: He is standing there,

As repetições na sala de aula de língua estrangeira têm um significado diferente das repetições em outros contextos. Portanto, devem ser compreendidas associadas à complexidade da situação comunicativa em que se inscrevem. No caso da sala de aula de língua estrangeira, em que a língua-alvo serve como veículo de instrução, esse recurso se reveste de fundamental importância. 
As repetições permitem que os alunos sejam expostos mais de uma vez aos enunciados na língua estrangeira. Na situação que analisamos neste estudo, elas ocorrem ora para possibilitar a compreensão ao oferecer o mesmo enunciado mais de uma vez, ora para reiterar respostas (servindo como avaliação da produção dos aprendizes), ora para esclarecer os pedidos que são feitos aos alunos.

Em todos esses casos, verifica-se um ajuste do discurso do professor à situação comunicativa de ensino-aprendizagem, que leva em conta o fato de os alunos encontrarem-se em estágio iniciante de proficiência no idioma estrangeiro, bem como o aspecto temporário da fala, que, ao contrário da escrita, só pode ser recuperada através da gravação, ou, nas interações propriamente ditas, através de repetições, modificações ou paráfrases.

Esse recurso amplamente utilizado pela professora não foi realizado conscientemente. Em entrevista informal, ela demonstrou surpresa ao verificar a quantidade de repetições realizadas durante uma sessão de aula. Mais tarde, em uma segunda entrevista informal. a docente disse ser essa a única maneira de se fazer entender na sala de aula, tendo em vista que o uso da língua materna tem de ser minimizado.

A professora também mostrou-se surpresa ao verificar que, nas transcrições e nas gravações da aula, o uso do idioma português realizou-se em duas ou três passagens apenas. Segundo ela, esse procedimento vai ao encontro do que preconiza a abordagem comunicativa de ensino de línguas - o uso da língua-alvo em situações de comunicação desde estágios iniciais de aprendizagem.

Em suma, a intolerância e a resistência às repetições, que persistem nas interações diárias, não se aplicam a contextos de ensinoaprendizagem de língua estrangeira em estágios incipientes de aprendizagem. Ao contrário, as atitudes em relação a esse recurso de interação são circunscritas ao contexto em que são utilizadas: para que ocorra a interação em sala de aula, torna-se necessário que o professor seja compreendido. Ao se expressar na língua estrangeira alvo, ele deve redobrar seus esforços para que seu pensamento seja seguido. Pode-se afirmar, de maneira geral, que, nesses contextos, a repetição faz parte do esquema de aula que professor e alunos possuem - àquele cabe ser claro na explanação de conteúdos, e estes esperam que aquele faça o esforço máximo para ser compreendido e dirimir dúvidas. 
Assim, as repetições são cruciais, pois permitem que alunos com maior dificuldade de compreensão auditiva acompanhem o raciocínio do professor em velocidade quase igual à da produção. Nesse grupo, consideramos essencial a repetição fonológica, que não foi explicitada na bibliografia consultada, mas parece importante ao estender o tempo de exposição dos alunos aos enunciados através do alongamento de sons, o que resulta na diminuição da velocidade de fala.

Além dessas funções, as repetições na sala de aula de língua estrangeira servem ainda como (a) clarificação de pedidos - que inclui a modificação e a paráfrase e (b) reiteração ou avaliação da produção dos alunos - feitas através da repetição. Na realização dessa última, o professor pode fazer alterações, que funcionam como avaliações retificadoras da produção dos alunos.

Em síntese, este estudo auxiliou na reflexão sobre os motivos da aceitação do discurso repetitivo do docente, bem como para verificar, junto ao participante, a consciência na realização desses processos. Em última análise, tornou explícitos processos linguiísticos inconscientes realizados pelo docente ao adaptar seu discurso para interagir com sucesso na sala de aula.

\section{Convenções para as transcrições}

$\mathrm{T}$

S

Professora

Aluno(a)

SS

Alunos(as) falando ao mesmo tempo

Entonação descendente, pensamento (parcialmente) acabado.

Entonação de fim de frase (sinalizando continuidade da fala).

Entonação ascendente; perguntas bipolares.

Prolongamento do som anterior. 


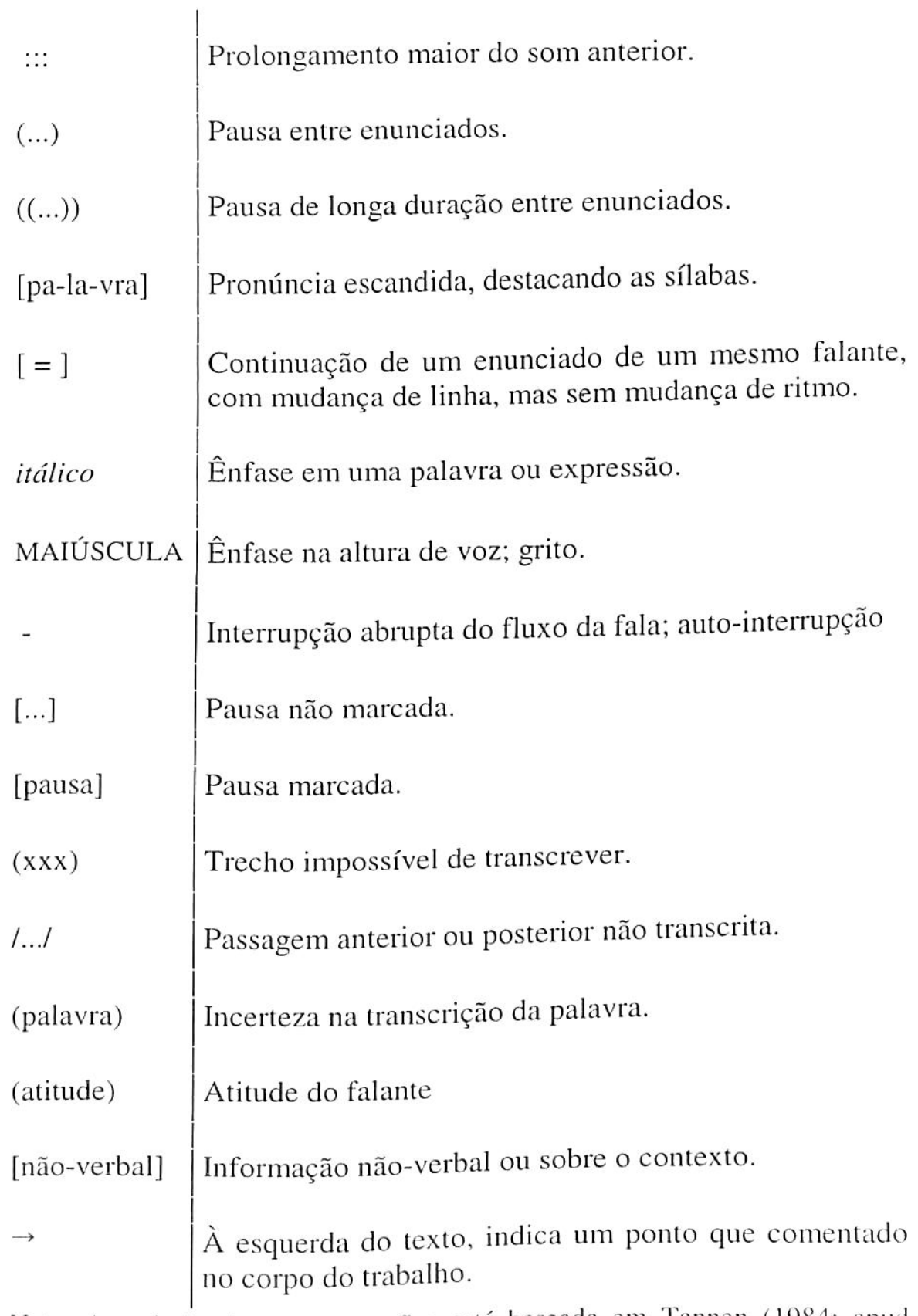

Nota: A maioria destas convenções está baseada em Tannen (1984; apud RIBEIRO, 1994). 


\section{Referências bibliográficas}

ERICKSON, F. Ethnographic description. In: AMMON, U; DITTMAR, N.; MATTHEIER, K. (Eds.). Sociolinguistics.v.2. New York /Berlin: Walter de Gruyter, 1988.

GRICE, H. P. Logic and Conversation. In: COLE, P.; MORGAN, J. (Orgs.). Syntax and Semantics: Speech Acts. NY: Academic Press, 1975.

GUMPERZ, J. Contextualization and understanding. In: DURANTI, A.; GOODWIN, C. (Eds.). Rethinking context. NY: CUP, 1992.

QUENTAL, L. A importância da pesquisa em sociolinguiística interacional para a realidade brasileira. Anais da Abralin, n. 6, 1996.

RIBEIRO, B. T. Coherence in Psychotic Discourse. New York: Oxford University Press, 1984.

SILVA, Simone. Metalinguagem em ensino de língua estrangeira. Dissertação de Mestrado, UFRJ. Rio de Janeiro, 1998.

TANNEN, Deborah. Talking Voices: repetition, dialogue, and imagery in conversational discourse. NY: CUP, 1989. Repetition in conversation.

TSUI, Amy. Introducing classroom interaction. London: Penguin, 1995. 